followed, a Committee on Termites was appointed, and the Conference adopted consequent resolutions in which it emphasised the heavy losses caused by termites and the lack of knowledge on them, and recommended the accumulation of data on the financial losses to buildings, agriculture and the forest industry, the identity and habits of the species involved, and methods of control. It also recom. mended that this matter be taken up with the Governments concerned with the view of providing for a thorough investigation of the whole problem.

In contrast to the above, Dr. Uvarov's paper was a report of progress on a subject on which a large amount of co-ordinated study has been carried on for several years. The possibility of preventing outbreaks of locusts is based on the fact that the swarming phase is produced from the solitary one under certain peculiar combinations of external conditions that occur at times in definite and rela. tively restricted areas. Once it is produced, the swarms spread over immense regions, and the invasion develops in spite of all efforts to stem jt. As a result of the extensive international organisa. tion of which the Imperial Institute of Entomology is the centre, records of the movements and breeding of swarms over the infested area of Africa and southwestern Asia are analysed, and from the data thus obtained field investigations are made to locate the centres in which the outbreaks arise, with the view of studying the ecological factors concerned in their commencement and the possibility of preventing it. It has thus been shown that the recent outbreak of the tropical migratory locust, which spread gradually over the greater part of Africa, originated in one or two restricted areas on the Middle Niger, and that the red locust similarly originated in a very few areas in Northern Rhodesia and Tanganyika Territory. Work on the desert locust has not progressed so far, but outbreak centres have been discovered on the coasts of the Sudan and of Baluchistan, and it is almost certain that none exists in the inner deserts of Africa. It will therefore be seen that the international investigations have provided a foundation for a preventive anti-locust policy, by which the outbreak centres can be kept under supervision and incipient outbreaks suppressed.

The discussion that followed afforded evidence that similar outbreak centres are characteristic of the principal injurious grasshoppers of North America and Australia.

\title{
Timber in the Box-Making and Coal-Mining Industries*
}

$\mathrm{I}^{\mathrm{N}}$ 1931, the Forestry Commissioners appointed an Inter-Departmental Committee to inquire into the possibility of making better use of the timber supplies of Great Britain. An interim report was submitted by this Committee in 1933, and recommended a series of detailed inquiries into the demand for timber for certain specific purposes. A first report dealt with the demand for timber for box and packing-case manufacture in Great Britain, whilst a second, now before us, deals with the demand for timber in coal-mining in England and Wales.

In the first report it was stated that there were two distinct sections of the industry, the box and packing-case makers on one hand, and the shookusing firms who merely assemble the component parts of the boxes already prepared, on the other.

So far as was observed, the timber used for shooks is invariably imported, and there was no evidence that home-grown timber could economically take its place either in character or quality. In the box and packing-case industry, home-grown timber, chiefly spruce and fir, is being extensively used in Scotland, and its suitability for many kinds of boxes is widely admitted in other areas, subject to various provisos. The Scottish firms are using it for mineral-water boxes and beer boxes, for the larger and heavier sizes of fish boxes, for soap boxes, for machinery cases, and cases for shipping rope and generally for any type of box in which light weight and a specially dressed appearance are not essential.

"The fact," says the report, "that, within the limits of the present enquiry, 20 per cent of the timber used by box making firms throughout Scot-

* Forestry Commission. Report on the Demand for Timber for Box and Packing-Case Manufacture in Great Britain. Pp. 47. (London: H.M. Stationery Office, 1934.) $9 d$, net

Forestry Commission. Utilization Series, No. 2 : Report on the Demand for Timber in Coal-Mining in England and Wales. $\mathrm{Pp}$ vi+77. (London: H.M. Stationery Office, 1935.) 18. $3 d$. net. land, and over $40 \%$ of the timber used by those in Aberdeen, is home-grown, is emphatic evidence that home-grown timber could be used more largely than it is in other areas if adequate supplies were available in good condition, and if the cost of transport did not make the price prohibitive." Even in Scotland, a number of criticisms of home-grown timber were made. Perhaps the chief, which certainly restricts its use for the finer and lighter types of packing-cases, is the question of the excessive quantity and size of the knots. The presence or absence of knots in home-grown or any other timber is purely a question of good sylviculture, which, with properly grown and tended plantations, should right itself in the future.

With the interest of the State in afforestation schemes during the past fifteen years, and the creation of State plantations extending to more than 250,000 acres, and with another 100,000 acres of privately owned woods, it is obviously desirable that outlets should be found to absorb the increasing supplies of material which will become available.

In the report on the demand for timber in coalmining, the report shows that the cost of mining timber annually consumed in Great Britain is about $£ 6,000,000$, and represents approximately a cost of $7 d$. on every ton of coal put on the market. Of this quantity, some 21 million loads were imported in 1934. It is said that an increase in the proportion supplied from native sources is possible immediately, and it can be substantially supplemented in the future from plantations at present immature.

The chief need is an effective scheme for marketing the home-grown supplies, and steps towards the attainment of this end have been taken in the formation of a Home-grown Timber Marketing Association under the chairmanship of Lord Clinton. 